\section{Edificio Histórico y Arqueología: un compromiso entre exigencias, responsabilidad y formación}

\section{Historical building and archaeology: a compromise between demands, responsibility and training}

Luis Caballero Zoreda

Instituto de Historia. CSIC. Académico del Partal. Madrid*

\section{Resumen}

Se analizan las características de pluriestratificado y pluritipologizado que definen al edificio histórico desde el punto de vista arqueológico. Estas características son las exigencias del Bien que crean un nuevo marco de referencia a la hora de relacionarnos con él, tanto el arqueólogo historiador como el arquitecto restaurador, y que, por tanto, nos marcan las condiciones imprescindibles a las que, como profesionales, tenemos que ajustarnos en el momento de la intervención/ conocimiento del Patrimonio construido y, de rebote, las condiciones de nuestra formación.

Esto es, dichas características plantean las exigencias del edificio histórico y las responsabilidades del arquitecto y del arqueólogo, de las que hasta ahora no éramos totalmente conscientes. Como tales responsabilidades se pueden ordenar en cuatro grupos de actividades profesionales que, a su vez, agrupan cuatro materias principales de nuestra formación: Interpretar, saber reconocer, conservar y comunicar las relaciones contextuales que autentican el edificio histórico.

Palabras clave: Arqueología de la Arquitectura; Historia del Arte; estratigrafía; tipología; estilo; originalidad; autenticidad; contexto; interpretar; metodología; conservar; comunicar.

\section{Abstract}

The characteristics of pluristratified and pluritypologised defining concepts of historical buildings from an archaeological point of view are here analyzed. These features are the heritage requirements which create a new reference frame within the historian archaeologist and the restorer architect relate to the building. These features define thus the indispensable conditions which determine the intervention and knowledge of building heritage and, indirectly, the training of the professionals in charge of it.

These characteristics show the requirements of historical buildings and the responsibilities of the architect and the archaeologist, who were not completely aware of them until now. These responsibilities may be ordered in four professional activities that also correspond to four main issues of training: interpreting, knowing how to recognize, preserving and transmitting the contextual relationships that make the historic building authentic.

Keywords: Archaeology of Architecture; Art History; stratigraphy; typology; stile; originality; authenticity; context; interpreting; methodology; preserving; transmitting.
La Arqueología ha sufrido un fuerte proceso de maduración en la segunda mitad del s. XX que prácticamente ha supuesto su refundación, tanto desde el punto de vista de la metodología como desde el de la teoría, reivindicando su propia concepción de la Historia a la vez que ha mejorado la utilidad como su herramienta auxiliar ${ }^{1}$.

Una de las consecuencias de este proceso de maduración, entre otras, ha sido la creación de una especialización que se ha dado en llamar Arqueología de la Arquitectura que es de la que vengo a tratar, una vez más, en este foro de arquitectos. En resumen, la Arqueología de la Arquitectura se puede entender como la aplicación del método arqueológico para la mejor comprensión de la arquitectura histórica. Pero también se puede definir como la concepción de la Historia de la Arquitectura desde la visión que ofrece la Arqueología.

Por otra parte, responsabilidad y formación se relacionan estrechamente entre sí, pues nos formamos al asumir responsabilidades y no podemos ser responsables nada más que de aquello que hemos asumido y por lo tanto en lo que estamos suficientemente formados como para salir de la empresa con ciertas posibilidades de éxito. Pero, ¿cuáles exigencias nos impone nuestro objeto de estudio y de intervención?, ellas son las que en realidad deberán marcar nuestra responsabilidad y nuestro nivel de formación.

Si ahora vinculamos la Arqueología de la Arquitectura con esta correlación entre las exigencias o los requerimientos del Bien, y la responsabilidad y la formación del arquitecto, podemos formular la siguiente pregunta, ¿qué deben reconocer los arquitectos desde el punto de vista de la Arqueología de la Arquitectura?, qué exigencias les marca el edificio considerado como documento arqueológico, qué responsabilidad tienen con el edificio histórico desde el punto de vista de la Arqueología de la Arquitectura, en qué se deben formar.

No es mi intención ofrecer aquí un temario pues además me consta la dificultad de transformar un programa de estudios. Su encaje, en suficiente proporción, en un programa de estudios no tiene por qué ser difícil, tanto en

\footnotetext{
${ }^{1}$ Este texto fue leído en el Colegio de Arquitectos de Cataluña. Ello explica ciertas referencias a un público y a una temática concreta, la de la formación del arquitecto. Dado que su publicación fue restringida, considero que no se vulnera la normativa de que esta sea inédita. CD. González Moreno-Navarro, J. L. (dir.), Profesiones y Patrimonio. Formación y responsabilidad. El caso de l@as arquitect@s. «XXX curset. Jornadas Internacionales sobre la intervención en el patrimonio arquitectónico" (Barcelona, diciembre 2007). Col-legi d'Arquitectes de Catalunya. AADIPA. Barcelona.

Agradezco los comentarios sobre el texto a Luis Caballero García y a Agustín Azkarate Garai-Olaun. También, sinceramente, los efectuados por los evaluadores normativos a los que contesto en nota, indicándolo en cada caso.
} 
un curso normal como en uno de postgrado donde ya suele tener una escasa presencia. Mi pretensión es abocetar unas líneas principales de lo que creo que un arquitecto debería reconocer y asumir en relación con la Arqueología.

Todos sabemos que la Arqueología se basa fundamentalmente en la estratigrafía. El edificio, al igual que las formaciones geológicas y los yacimientos, se conforma por estratos. Por razones naturales y fundamentalmente antrópicas, sucesivos estratos sustituyen a las partes arruinadas que han dejado su huella en forma de superficies de corte; superficies que, aunque incorpóreas, tienen el mismo valor que verdaderos estratos. Por ello decimos que los edificios históricos son objetos pluriestratificados o que los edificios pasan a ser considerados históricos desde el momento en que son pluriestratificados. La estratigrafía, que estudia estos procesos, aportada desde la Geología a la Arqueología, es el método más específico de la Arqueología de la Arquitectura.

El proceso de cambio y formación estratigráfica del edificio viene acompañado de un cambio en las características de esos estratos. Parangonando con la estratigrafía geológica podemos decir que los fósiles que contienen la secuencia de estratos van cambiando o evolucionando con ellos. Sólo que en la arquitectura estos fósiles son específicamente los propios estratos (aunque también existen objetos que cumplen la función similar a la de los propiamente fósiles, como los elementos decorativos o intrusiones, por ejemplo cerámicas, aportadas con los materiales constructivos). Estos fósiles/estratos son básicamente los materiales constructivos y la forma de aparejarlos o los aparejos, elementos que se ordenan en tipos y que son objeto de estudio del otro método típicamente arqueológico, la tipología. También podemos considerar tipos los sistemas estructurales y las formas arquitectónicas.

La tipología no es menos importante que la estratigrafía, primero porque cuando los estratos no están claramente definidos, es a través de sus características como los podemos diferenciar («clusters» de Agustín Azkarate 2002: 67-69); y segundo porque los tipos, al repetirse, se pueden datar como indicadores cronológicos absolutos, esto es provistos de una datación concreta que los estratos por sí mismos no tienen (ya que son indicadores cronológicos relativos). Esta es otra razón por la cual estratigrafía y tipología son complementarias.

Por tanto damos por supuesto que los edificios históricos, en tanto en cuanto que históricos y sin excepción, son objetos pluriestratificados y plutitipologizados. Pero esto es algo que, como hemos dicho, ya dábamos por conocido. Lo que nos interesa es saber cómo repercuten estas dos características en las prácticas arquitectónica e histórica.

Ser conscientes de que los edificios son pluriestratificados y pluritipologizados supone conocerlos de un modo distinto a como hasta ahora se venía haciendo. Significa reconocer que ningún edificio histórico representa un edificio modelo, con las características cerradas de un prototipo en todas sus partes. En el mejor de los casos esto sólo ocurrirá en algunas de ellas, en alguno de sus estratos que, de modo excepcional, puede ser predominante o mayoritario en el volumen total del edificio. Al contrario, el edificio histórico está conformado por «modelos» distintos y parciales que se suman unos a otros y se ajustan entre sí. Sólo el edificio originario, en el caso de que se hubiera terminado por completo, fue en el momento de su construcción un modelo completo y esto, paradójicamente, antes de pasar a ser realmente, por causa de su ruina y posterior restauración, un edificio histórico. Ninguno de los demás «edificios» que, como he dicho, se fueron superponiendo al originario es completo en el sentido cierto de la palabra, de modo que la estructura real resultante, una vez que se ha hecho verdadero edificio histórico, es una suma de modelos incompletos y parciales.

Procurando no enredarme más en este juego de palabras terminaré por señalar que la comprensión ideal del edificio como modelo se hace desde la consideración de lo original. El observador procura reconocer en cada uno de estos modelos parciales cómo sería un original ideal o una serie de originales históricos que en realidad no existen. Al contrario, la observación del edificio como una estructura real, suma de partes, se hace desde la consideración de lo auténtico, parcial, incompleto, añadido. Esta autenticidad viene definida por las relaciones, «auténticas», que mantienen entre sí las partes de esos edificios originales parciales que le conforman (concepto que debo a Doglioni 2002: 114; Caballero 2006a: 171-173).

La idea de relaciones de autenticidad encaja perfectamente con la manera en que la Arqueología comprende la cultura material, donde lo que realmente interesan no son los objetos aislados sino las relaciones que estos mantienen entre sí y con el conjunto, conformando lo que llamamos «contexto». No interesa tanto contemplar en el edificio características que vamos a considerar propias e inamovibles de él, que serían propias de cada original ideal; como, al contrario, lo que interesa observar en él son las relaciones que mantienen las partes de cada una de sus unidades entre sí y con las demás unidades. Cuáles son las relaciones que 
existen entre las partes que son diferentes y que por ello mismo dejan de ser características y propias del objeto final pues lo propio de él es justamente la variabilidad. Lo que interesa es, por tanto, cada sistema de unidades relacionadas y el proceso de esas relaciones. Estas relaciones contextuales son las que permiten la lectura del conjunto material como si se tratara de un texto escrito (método filológico). Efectivamente, el edificio histórico lo consideramos un contexto conformado por objetos originales que se relacionan entre sí y que permiten lecturas muy variadas donde cada parte es diferente y cumple una función específica en un sistema significativo, complejo y procesual.

Citemos ahora sólo algunas de estas posibles y múltiples lecturas del edificio:

La lectura cronológica. Las relaciones de anteroposterioridad entre esos estratos originales permiten ordenarlos en una secuencia temporal donde sabemos qué fue lo más antiguo y qué es lo más moderno. Las relaciones tipológicas otorgan un valor cronológico absoluto a las relaciones temporales relativas de los estratos, como ya hemos dicho.

La lectura funcional. Las relaciones entre las partes de cada original permiten comprender sus funciones y cómo estas fueron cambiando y transformando progresivamente las del edificio originario.

La lectura estructural. Aunque la estructura más patente sea la última conservada, sin embargo, por sus relaciones de dependencia con las partes originales más primitivas, podremos comprender cuáles eran las estructuras suprimidas o supervivientes y cómo se dio el proceso de cambio estructural.

La lectura productiva. El edificio se nos aparece como un proceso de producción, de productos constructivos que han evolucionado a lo largo del tiempo. Los productos originales han ido variando a la par de la evolución social, estructural y formal.

La lectura cultural. Las lecturas anteriores son inmediatas; interpretan el edificio como un conjunto transformado material, estructural, funcional y artísticamente en diacronía. Pero la principal lectura que se puede hacer del inmueble es la cultural. Cada uno de los contextos sincrónicos que lo configuran y sus interrelaciones informan al historiador y a la sociedad, mediante su puesta en valor, de las formas de vida, ritos de paso, organización familiar, formas de relación social o ideología de las diversas culturas que lo han habitado. En este sentido, la conservación del edificio se justifica porque nos permite conocer y sobre todo comunicar de modo más efectivo como ningún otro documento las culturas que conforman nuestro pasado.
Observemos el riesgo que conlleva la consideración de la originalidad en el edificio histórico, por su tendencia que obliga a considerar todo el edificio como un único original, suprimiendo u omitiendo en la observación o en la intervención todo lo que se escape del modelo ideal. Al contrario, la autenticidad, al obligarnos a considerar la realidad, nos empuja a valorar por igual a todas las unidades por escaso valor que parezcan tener pues lo que realmente nos interesa no son estas unidades sino las relaciones significativas que comportan. Es evidente la importancia y la consiguiente responsabilidad que tiene adoptar uno u otro punto de vista, tanto en el análisis histórico como en la intervención restauradora. Llevándolo a la exageración, asumir el punto de vista de lo original supone preferir el purismo que limpia el edificio para recrear un edificio modelo que nunca ha existido. Al contrario, el punto de vista de las relaciones obligaría, llevado al extremo, a mantener intacto el edificio y a no tocarlo ante el miedo de que se perdieran esas relaciones que lo autentican, lo cual en la práctica es imposible. Pero mientras que una exagerada comprensión de las relaciones lo único que provoca es la conservación a ultranza de todos los elementos; una mal entendida originalidad conllevará la irreparable pérdida de la autenticidad del edificio y con ello de unidades cuya importancia desconocemos pues no habremos tenido en cuenta el valor de sus relaciones. Esta es la desafortunada restauración que llamamos "purista»: así se nos presenta de golpe la responsabilidad del arquitecto restaurador enfrentado al verdadero valor del documento construido, a la necesidad de reconocer, de efectuar y de tener en cuenta la lectura completa de las relaciones que mantiene el edificio.

Podemos observar que hemos conseguido un juego de conceptos contrapuestos, esto es, el del edificio modelo o ideal, considerado desde el punto de vista de lo original; frente a la estructura real, considerada desde el punto de vista de las relaciones auténticas que mantienen sus partes. Este juego dicotómico lo podemos completar con dos conceptos más; el del estilo para el edificio modelo y el del tipo para la estructura real2 ${ }^{2}$.

El edificio considerado como modelo o considerando lo que tiene de original se caracteriza por su estilo. Decimos, «este edificio es típico del Renacimiento, sus características son típicas renacentistas», haciendo abstracción inconsciente de que en realidad son sólo algunas de sus características las que son renacentistas y que las demás,

${ }^{2}$ En realidad es la tipología la que se enfrenta al estilo, y también la estratigrafía. La Historia del Arte asiste con el bagaje del estilo y la Arqueología con el de la estratigrafía y la tipología. 
aunque apenas nos sean perceptibles, son tan importantes como las primeras; que lo que realmente nos interesa no son aisladamente estas o aquellas, sino el cómo y el por qué cambiaron de unas a otras.

\begin{tabular}{c|c} 
HisTORIA DEL ARTE & ARQUEOLOGía \\
\hline Edificio modelo & Estructura real \\
\hline Originalidad & Autenticidad \\
\hline El estilo & El tipo
\end{tabular}

Esta nueva pareja de contrarios es lo que nos permite darnos cuenta con nitidez del cambio operado. El estilo es el núcleo conformador de la Historia del Arte, mientras que es el tipo lo característico de la Arqueología. También son propios de la Historia del Arte el edificio modelo y lo original. Y al contrario, lo son de la visión arqueológica la estructura real y la comprensión de las relaciones como lo que carga de autenticidad al edificio histórico.

Podríamos achacar estas diferencias también a la Historia de la Construcción considerada como historia de las estructuras. Así es, mientras que las estimemos apropiadas para un edificio que habría sido construido desde el principio dedicado a ellas; sin darnos cuenta de que esas estructuras no eran adecuadas para otras características heredadas por el edificio y que, por lo tanto, fueron fuente de cambios internos y de problemas y daños estructurales sobrevenidos.

Estoy así terminando de redondear el primero de los puntos sobre el que quería llamar la atención. La Arqueología ofrece a la Arquitectura una manera diferente de mirarse de la que hasta ahora ha sido la tradicional. Ello debe dar lugar a una Historia de la Arquitectura nueva; frente a la Historia de los estilos o de las estructuras, una Historia de los procesos constructivos derivada de la historia particular de los «edificios superpuestos». Procesos estratigráficos y tipológicos que pueden leerse como procesos de cambios formales, cronológicos, funcionales y, sobre todo, productivos y culturales. Una historia social de la producción arquitectónica y constructiva. Por ejemplo, por qué y de qué manera unas murallas se convirtieron en una catedral (catedral de Vitoria) o por qué ciertas salas capitulares se convirtieron en cajas de escaleras (Santa María la Real de Aguilar de Campoo) o por qué ciertos aparejos cambiaron mientras que otros aparentemente se mantuvieron a través de los siglos como un símbolo social asociado al poder (la soga y tizón en Córdoba). O cómo fue el proceso de cambio y por qué cambia la estructura de la mezquita a la iglesia con la conquista.
Antes de seguir quiero hacer un paréntesis obligado y salir al paso de quien considere que mi pretensión es la de demostrar obsoletas las Historias del Arte y de la Construcción y sus conceptos de estilo y de estructura. Esto no es cierto. La Arqueología enriquece nuestra metodología y abre un horizonte nuevo, añade una mirada nueva pero no invalida, pese a lo que algunos puedan considerar, los horizontes ya recorridos con éxito por el estilo y la estructura y que mantienen su importante papel. Lo que sí debemos considerar es que la visión arqueológica complementa y revaloriza la visión de estas Historias y que éstas ya no se pueden efectuar aisladas y deben complementarse con la nueva visión histórica que nos ofrece la Arqueología.

A continuación debería hacer otra nueva digresión definiendo y comparando los conceptos de estilo y de tipo y buscando sus diferencias. Pero no es ésta mi intención. Sólo observaré que el estilo actúa como un modelo cerrado de difícil mudanza al que sometemos la observación de los datos para, de acuerdo con si se ajustan o no a él, incluirlos o segregarlos. Al contrario, el tipo funciona observando los datos para ir creando y recreando tipologías abiertas y variadas que interactúan y se verifican entre sí.

Esta distinta manera de actuar supone una serie de consecuencias. Mientras que el estilo tiende a unificar en la observación todo como semejante; el tipo observa con mayor meticulosidad las diferencias. No es raro por ello que un análisis tipológico distinga el que objetos que se agrupaban como pertenecientes a un mismo estilo, en realidad pertenecen a grupos diferentes o incluso a imitaciones o pastiches modernos realizados justamente para unificar la observación artístico-estilística engañando al observador. La disección a que obliga la observación tipológica hace profundizar allí donde al estilo no le es posible profundizar más ${ }^{3}$. De esta manera, características desapercibidas por principio por el estilo son en cambio típicas de la tipología, por ejemplo las huellas de las herramientas, o las formas de aparejar materiales. Esto hace que la información tipológica corra paralela e independiente a la del estilo en caminos divergentes. Lo mismo ocurre con características dadas como típicas de estilos determinados y que el análisis estratigráfico-tipológico se empecina en demostrarnos que pertenecen a otro momento, incluso aunque se trate de estructuras básicas del edificio.

\footnotetext{
3 Es el caso, por ejemplo, de los perfiles de las "puntillas» de los arcos y el antepecho del triforio de la catedral de Vitoria, en los que se pudieron diferenciar hasta cuatro variables tipológicas, pertenecientes a otros tantos conjuntos (o "clusters») constructivos. Sin embargo, el análisis de "estilo» llevó a los historiadores del arte a considerar la obra unitaria. Azkarate y Lasagabaster 2001: 549, fig. 3a.
} 
Finalmente, la tipología, ya sea de caracteres formales, constructivos o funcionales, y la estratigrafía de consuno definen una ordenación de la realidad material de los edificios que supera las ordenaciones tradicionales de los periodos históricos y de los estilos artísticos. Son las propias características de las unidades del edificio las que ordenan su historia, alargando o acortando lo que parecían etapas sincrónicas históricas o estilísticas, siglo a siglo en intervalos metronómicamente regulares, o estilo a estilo aparentemente estancos e igualitarios. Por ejemplo, un aparejo se compagina con otros aparejos tan diferentes que podríamos separarlos como pertenecientes a momentos históricos distintos si no fuera porque sus relaciones se empeñan en demostrarnos que son coetáneos; o, al contrario, se alargan en el tiempo de un modo conservador, engañando al observador no avisado como si todo el edificio fuera un mismo original. De esta manera, estratigrafía y tipología permiten la distinción de micro y macro tiempos (cortos y largos) de carácter básicamente social y cultural. El tiempo arqueológico se alarga o se acorta en función de consideraciones materiales intrínsecas a los objetos y a sus relaciones, que se independizan $y$, aunque terminemos encuadrándolas en modelos previos históricos o artísticos, sin embargo ni hacen referencia ni en realidad se ajustan a ellos.

La tipología (que redundantemente se suele denominar "cronotipología», como si la tipología no fuera cronológica por sí misma ${ }^{4}$ ) representa un campo de investigación de horizontes insospechados tanto para arquitectos como para arqueólogos, que ya ha empezado a dar sus frutos (Azkarate y Sánchez Zufiaurre 2005; Sánchez Zufiaurre 2007).

\footnotetext{
${ }^{4}$ El evaluador me achaca la incomprensión o la crítica incorrecta del término "cronotipología». Efectivamente, reitero que no sólo creo innecesario adjetivar con el prefijo crono- el sustantivo tipología, sino que hacerlo me parece peligroso. Parecería, en primer lugar, que sólo la tipología está cargada de cronología, lo que no es cierto. La tipología es uno más de los «indicadores cronológicos», junto a la estratigrafía, las fuentes escritas y la arqueometría (que, si acaso, deberíamos denominar también cronoestratigrafía, cronodocumentación y cronoanalítica). Es más, la tipología es cronológica gracias a la ayuda de las otras tres «estrategias» (Parenti 1985). Tampoco es argumento válido, a mi parecer, suponer que en momentos historiográficos pre-arqueológicos se realizaran mal consideradas tipologías, en realidad ordenaciones de características estilísticas que la investigación del momento, lógicamente, no podía cargar de valor secuencial o cronológico. A este respecto quiero añadir que no se debe confundir el primer estadio de construcción de una tipología, cuando es una mera serie de objetos característicos, con su estadio final, ya puesta en fase y en constante renovación y mejora. Cuando reparo en la reiteración con que se emplea el término "crono-tipología" tengo la impresión de que se sobrevalora una mal entendida "cronología absoluta" (tipología) frente a una capitidisminuida "cronología relativa» (estratigrafía), sin tener en cuenta que lo que realmente interesa es "contextualizar» los indicios cronológicos de uno u otro tipo, lo que normalmente se obtiene, curiosamente, gracias a la estratigrafía. Sobre "cronotipología», ver especialmente Ferrando, Mannoni y Pagella 1989; Gabrielli 1996; Quirós 1996; Mannoni 1997.
}

Hemos observado hasta aquí, desde el punto de vista de la Arqueología, unas características que definen al edificio histórico. Estas características son las exigencias del Bien que crean un nuevo marco de referencia a la hora de relacionarnos con él tanto el arqueólogo historiador como el arquitecto restaurador y que, por tanto, nos marca las condiciones imprescindibles a las que como profesionales tenemos que ajustarnos en el momento de la intervención/ conocimiento del Patrimonio construido y de rebote las condiciones de nuestra formación (el momento de la intervención es el momento de la investigación, Francovich 1985 y 1988; Azkarate 2002; Caballero 2002; comentados en Caballero 2006a: 163-164).

Esto es, las características de pluriestratificado y pluritipologizado plantean las exigencias del edificio histórico y las responsabilidades del arquitecto y del arqueólogo, de las que hasta ahora no éramos totalmente conscientes. Como tales responsabilidades se pueden ordenar en cuatro grupos de actividades profesionales que, a su vez, agrupan cuatro materias principales de nuestra formación: Interpretar, saber reconocer, conservar y comunicar las relaciones contextuales que autentican el edificio histórico.

\section{INTERPRETAR}

Es en la interpretación donde mejor se entrelazan la parte más teórica, expuesta hasta aquí en esta exposición, y, por tanto, lo que son las exigencias del Bien y la responsabilidad de los profesionales. Conforma en realidad el marco de referencia a que nos acabamos de referir. Como tal marco de referencia o teoría previa va bien que se coloque delante, pero como proceso de interpretación debería ir en segundo lugar, después de la toma de datos a que se refiere el reconocimiento5.

Ya lo hemos repetido reiteradamente: se trata de las implicaciones que conllevan los nuevos conceptos de pluriestratificado y pluritipologizado que para nosotros definen el edificio histórico. La comprensión del edificio histórico formado por relaciones que le autentican y que determinan nuevas ordenaciones de sus elementos, una nueva Historia de la Arquitectura y la responsabilidad de reconocer y conservar las relaciones contextuales.

\footnotetext{
${ }^{5}$ Entiendo que el evaluador me insta a explicar cuándo la interpretación es previa al proceso investigador. Sin un modelo explicativo previo es imposible realizar la investigación. En este sentido, la interpretación, entendida como marco de referencia, es previa. Sin embargo, el propio proceso de conocimiento, si está correctamente efectuado, nos puede obligar, en segundo lugar, a variar aquel modelo reformándolo, «falsándolo» o contradiciéndolo por completo con una interpretación nueva.
} 
- El concepto de estratigrafía (frente al utópico edificio unitario). El edificio como objeto pluriestratificado. Las relaciones físicas y temporales.

- El concepto de tipología (frente al de estilo). El edificio como objeto pluritipologizado. Las relaciones formales, funcionales y productivas.

- La autenticidad (frente a la originalidad) como observación relacional, esto es de las relaciones entre las partes, los todos que forman el edificio y él mismo.

- El concepto de contexto donde toman significado los sistemas de unidades que conforman un edificio, espacial, temporal, funcional y culturalmente. Pero también él mismo y su entorno (el urbanismo) como contextos.

- El concepto de proceso y consecuentemente de producción. El edificio como producto constructivo histórico.

- El valor de la ordenación material (frente a las ordenaciones del tiempo histórico y del estilo artístico).

- Una nueva comprensión de la Arquitectura y de la Historia de la Arquitectura ${ }^{6}$.

\section{UTILIZAR CORRECTAMENTE LA METODOLOGÍA ARQUEOLÓGICA ${ }^{7}$}

El reconocimiento arqueológico viene dado por la utilización correcta de la metodología arqueológica. Esta metodología supone un avance en el rigor analítico, en concreto frente a la metodología de la Historia del Arte.

Específicamente se trata de la metodología estratigráfica (método Harris). Pero no debemos olvidar que la

\footnotetext{
${ }^{6}$ Azkarate, 2006: 139-145, hace un esbozo, desde el punto de vista de la "arquitectura invisible», de lo que empieza a ser esta nueva Historia de la Arquitectura. Arquitecturas inmateriales, definidas por el vacío de las zanjas de robo; arquitecturas efímeras de madera y excavadas en la tierra; arquitecturas enajenadas por su pobreza o humildad frente a las consideradas nobles o simbólicas; arquitecturas veladas que no son lo que parecen (o que parecen lo que no son); y arquitecturas olvidadas, literalmente arrinconadas. Pero este esquema, dentro de su validez, es sólo un inicio. Debe completarse con las experiencias particulares que nos están dando los edificios analizados, sobre todo de los procesos de reutilización y de cambio de uso que no son exclusivos de cada edificio sino que se repiten bajo patrones reiterativos de carácter social y económico (al que pertenece el citado como «no es lo que parece»).

7 Este apartado se denominaba originalmente «Saber reconocer» y ha sido el único cambio de importancia hecho en el texto originario. El evaluador me instaba a subrayar o desarrollar la relación, expresada por mí, entre «interpretar» y «saber reconocer». Sin embargo, en este apartado no pretendo seguir desarrollando el «cómo» reconocer (ya visto en el anterior, «interpretar»), sino que pretendo enfatizar el «saber» reconocer; esto es, reitero, la correcta utilización del instrumento «arqueología de la arquitectura». De nada nos valdrá este instrumento (método, metodología) si cada uno lo utilizamos de un modo incorrecto o antagónico, despreciando su función profesional. Comprobado lo equívoco del título he optado por cambiarlo.
}

tipología tiene su propia metodología por más que no esté tan extendida como lo está universalmente la de la estratigrafía. El ejemplo más cercano de la metodología tipológica es la de «variables de conjuntos» de Agustín Azkarate (o «clusters»; 2002, ya citada). Pero, a mi parecer, la importancia real de esta propuesta de Azkarate reside en la utilización simultánea o alternativa de los dos instrumentos, ajustándose a las circunstancias de cada edificio y a los objetivos del análisis que se efectúa. Del mismo modo debemos tomar en consideración los métodos propios de las Ciencias Naturales y de las Ciencias Documentales, utilizadas por la Arqueología como auxiliares, pero que, en cualquier caso, para que sus resultados sean válidos y comparables, se han de adaptar a los principios de la interpretación ya dichos, especialmente a los de autenticidad y de contexto.

Es responsabilidad nuestra utilizar correctamente los instrumentos estratigráfico y tipológico. La metodología estratigráfica conlleva ante todo la aceptación de unos principios deposicionales. En el proceso de trabajo se utilizan fichas analíticas que ayudan a la diferenciación de unidades estratigráficas, entre las que tienen especial importancia en Arquitectura las superficies, y los tipos. La lectura, ya sea estratigráfica y/o tipológica, conlleva saber interpretar las relaciones contextuales. Los diagramas y las planimetrías ordenan estas relaciones, las sintetizan y ayudan a su comprensión.

Nuestro colega arquitecto Antoni González ha llamado la atención sobre la problemática relación de este método con los arquitectos, inventando la irónica figura del «arquitectólogo» que se podría completar con la opuesta del «arqueotecto». ¿Puede y debe ser este método propio también del arquitecto restaurador? o ¿conlleva condicionantes que hacen imposible su utilización por un arquitecto y obligan a que sólo lo utilice el arqueólogo? En este debate mi posición parte de que la estratigrafía ha sido un método exportado de la Geología y que del mismo modo puede y debe ser trasladado a otras profesiones como a la de arquitecto restaurador. Ricardo Francovich (1988: 18) afirmaba con toda razón que éste es «el mejor de los métodos de que disponemos» y que por lo tanto sobra la discusión sobre quién puede utilizarlo. Importantes arquitectos, como el italiano Francesco Doglioni ${ }^{8}$, son indudables expertos en la teoría y la práctica de la estratigrafía arquitectónica, a pesar de que la acomoden a su práctica profesional. Sin embargo, Geología y Arqueología compar-

${ }^{8}$ El evaluador me pide que haga referencia al reciente trabajo de Doglioni, 2008. Añado el del mismo autor de 1997, ambos de interés para el arquitecto restaurador y para el arqueólogo de la arquitectura. 
ten su carácter de «históricas», lo que obliga a considerar al arquitecto estratígrafo como necesariamente interesado en la vertiente histórica de su actividad. La actuación arqueológica necesita especializaciones que llegan a ser impensables en los arquitectos, especialmente la de la excavación del subsuelo, pero también otras como la ceramología. Si el arquitecto se reserva el edificio, el arqueólogo se vería relegado de nuevo al yacimiento (recuperando el horizonte del suelo el carácter de frontera diferenciadora entre la infraestructura, para el arqueólogo, y la estructura, para el arquitecto) con lo que se rompería no sólo la tan deseada unidad de intervención, sino también la unidad interdisciplinar del equipo del que contradictoriamente se separaría al arqueólogo. Además y pese a todo, considero irrenunciable que los arquitectos conozcan el método, al margen de que lleguen a practicarlo en mayor o menor medida. Sólo su conocimiento les permitirá comprender su necesidad, su proceso, sus conclusiones y sus implicaciones (Azkarate 2004; Caballero 2006a: 165-166; Id. 2006b: 35, nota 3)9 .

$\mathrm{Si}$ es importante mantener viva la discusión metodológica, no lo es menos el consenso o la normalización metodológica en que se fundamenta la necesaria coherencia profesional. En el momento actual hay abiertas dos discusiones muy similares sobre el principal instrumento, el diagrama o «matrix Harris». Una sobre la correcta representación de la secuencia de "edificios superpuestos», grupos de Unidades Estratigráficas (que llamamos por norma Actividades) obsoletas y reutilizadas por otras posteriores en el dilatado proceso de construcción del edificio histórico: la Actividad más moderna utiliza coetáneamente los restos de Actividades arruinadas y desechadas y esto no lo representa el diagrama, problema tanto de la excavación como de la lectura del edificio. Y otra sobre su limitación al registrar procesos de deterioro que actúan parsimoniosamente a lo largo del tiempo sobre unidades y estructuras que pertenecen a tiempos distintos (resúmenes en Caballero 1997: 319-321, cuadro 3 y Azkarate 2002: p. 58 n. 1) ${ }^{10}$.

\footnotetext{
9 Dado el valor como «documento» del edificio histórico y del carácter destructivo de la intervención restauradora, se hace necesario, a mi parecer, una urgente normativización (legislación) de esta relación del arquitecto con la arqueología de la arquitectura, que recoja además la «excavación» del edificio por el profesional arqueólogo y su co-participación en el proyecto de intervención del edificio histórico.

${ }^{10} \mathrm{El}$ primer problema se considera tan importante que ha intervenido el mismo Harris (2003, comentado por Parenti, Giannichedda y Medri, Archeologia dell' Architettura, 2003, 8 y 2004, 9). Mi opinión es que se trata de un problema artificial que no se puede achacar al diagrama. No se puede pedir a los instrumentos que ejecuten funciones para las que no están preparados. Se debe buscar la solución, cuando sea necesario, en otros instrumentos, como fichas o listados sintéticos de Actividades o, más simplemente, en una correcta utilización de la Memoria.
}

\section{CONSERVAR}

Si suponemos que lo que autentica un edificio son sus relaciones y que éstas tienen tanta o mayor importancia que las Unidades que lo componen, la conclusión es que los arquitectos están obligados a la conservación de estas relaciones en la intervención restauradora. Ya existe teoría y práctica sobre este punto de vista «arqueológico» de la restauración, desarrolladas por arquitectos restauradores que están familiarizados con la Arqueología de la Arquitectura, cuyo resumen hemos expuesto en otros lugares (Caballero 2006 a y b), y que debería ser tenido en cuenta de modo muy especial en la formación del arquitecto:

- Brogiolo y el principio del registro (1995): «el 'diagrama periodizado' (instrumento que define las relaciones) se convierte en 'diagrama de proyecto' mediando entre el equipo que genera conocimiento (el arqueólogo) y el equipo que decide la intervención (el arquitecto) ${ }^{11}$.

- Latorre y Cámara y el principio de la inmovilidad de los materiales (2002): "El movimiento de los materiales de su sitio original, al originar la pérdida de sus valores documentales, asociados a los materiales removidos, y la desaparición de las relaciones estratigráficas que mantenían entre ellos y los demás materiales, provoca el empobrecimiento de las relaciones estratigráficas y del efecto evocador del paso del tiempo en el edificio". Por ello "Los monumentos deberán ser tratados como yacimientos arqueológicos y la eliminación del material constructivo en los proyectos de restauración deberá supeditarse a la metodología arqueológica, lo que obligará a su documentación exhaustiva y a efectuarse siguiendo los contornos de la estratificación".

- Doglioni y el principio de la autenticidad estratigráfica (2002): es de Doglioni de donde hemos aprendido el concepto de autenticidad ${ }^{12}$. La estrati-

\footnotetext{
11 De nuevo el evaluador solicita que aclare este "principio", lo que puede efectuarse mejor acudiendo a los textos del profesor Brogiolo, prestigioso historiador y arqueólogo medievalista. El "diagrama periodizado», expresamente dedicado a definir y secuenciar los distintos originales que componen el edificio histórico, se transmuta en "diagrama de proyecto» cuando el arquitecto se aprovecha de él para diferenciar la intervención restauradora concreta que requiere cada uno de esos originales delimitados estratigráficamente con precisión, de modo que se decide su destrucción, conservación, enfatización o incluso recreación, de acuerdo con su valor documental y significativo.

${ }^{12} \mathrm{El}$ evaluador requiere que aclare el concepto de "autenticidad», al que ya me he referido antes. De nuevo reitero que lo mejor es acudir al propio Doglioni, pero, mientras, procuro aclarar que el edificio histórico es "auténtico» en tanto que mantiene y ofrece las relaciones (constructivas, destructivas, reconstructivas) de los distintos originales que lo componen. Ocultar o falsear estas relaciones o,
} 
ficación equivale para Doglioni a «la autenticidad del edificio histórico» pues constituye su "condición constitutiva» de tal y determina su "estructura relacional». Por lo tanto, «la conservación de la estratificación es un fin primordial (o una condición obligatoria) de la restauración». De este principio dependen otros tres que hemos resumido así:

1) el tratamiento de las superficies es fundamental para ocultar, mantener o reconocer la estratigrafía (importancia de las superficies);

2) la restauración debe aplicarse como estratificación intencionada; $y$

3) deben salvaguardarse especialmente las trazas de alta potencialidad informativa (esto es, aquellas en las que se concentra una alta capacidad documental o histórica).

Los arquitectos se deben responsabilizar por una parte de que no se pierde la lectura del documento histórico construido, la hagan ellos o los arqueólogos. Esta es una condición sine qua non previa a cualquier tipo de intervención, ya sea conservadora o innovadora, y que debería incorporarse a las leyes de Patrimonio. Y por otra parte, deben responsabilizarse de aplicar en sus intervenciones una "mentalidad estratigráfica» en la terminología de Doglioni; esto es, deben aceptar la responsabilidad de conservar las relaciones contextuales del edificio.

Aprender a aplicar estas normas, y las de otros arquitectos que investigan y ya practican la Arqueología de la Arquitectura (Mileto y Vegas 2006), debe formar parte también de la responsabilidad y la formación de los arquitectos.

\section{COMUNICAR}

La lectura arqueológica de los edificios históricos requiere una rígida «disciplina» que obliga a contemplar el edificio como un todo: no basta con una mirada entrenada. Estratos y tipos aparecen y desaparecen y nos engañan confundiéndose entre sí. Sin someternos a la disciplina de un método riguroso es imposible conseguir la lectura. Y si esto es difícil para el especialista, lo es más para el no experto. Pero, siendo esto cierto, no encierra ni mucho menos la razón de por qué es importante comunicar. El bien cultural (el edificio histórico en nuestro caso) tiene un valor social como documento que nos vincula a nuestro

simplemente, destruir alguno de estos originales hace que el edificio histórico deje de ser tal y, por tanto, pierda dramáticamente su autenticidad. Ello no obsta para que el nuevo arquitecto, intencionadamente, enriquezca el valor histórico del edificio con nuevas relaciones al añadirle un nuevo original. pasado simbólica, física, emotiva e intelectualmente, permitiéndonos reflexionar sobre nosotros mismos y proyectar al futuro nuestra visión de la sociedad. Cualquier profesión que trate con el patrimonio debe tener claro estos dos valores, documental y comunicativo o social, del mismo, y comprometerse a preservarlos y actualizarlos. No es el patrimonio material lo que es de todos, por más que deba de serlo en cierto modo, son sus significados y nuestro derecho a reflexionar sobre los mismos y desde ellos sobre nosotros, lo que arqueólogos, restauradores y arquitectos debemos comprometernos a preservar y comunicar. ¿Cómo hacerlo? Desde luego contando con los expertos en comunicación, sin cuya ayuda será imposible que nosotros lo consigamos, pero también no olvidando que éste debe ser objetivo inexcusable de todas nuestras intervenciones. Propuestas como las de Doglioni sobre descubrir y conservar la autenticidad del edificio están (o deben estar) estrechamente ligadas con la comunicación social de las relaciones entre sus partes y de sus significados. Una asignatura más pendiente de desarrollo.

\section{Bibliografía}

Azkarate, A. y Lasagabaster, J. I. 2001: La catedral de Santa María. Análisis constructivo, I Congreso europeo de restauración de catedrales góticas, Vitoria, 547-560.

Azkarate, A. 2002: Intereses cognoscitivos y praxis social en Arqueología de la Arquitectura, Arqueología de la Arquitectura, 1, 55-71.

Azkarate, A. 2004: La interdisciplinariedad, ¿una concesión al lenguaje políticamente correcto?, "Qué está pasando (?). Condicionantes, teoría y praxis actuales del ejercicio de la restauración monumental», $2^{a}$ Bienal de la Restauración Monumental (Vitoria 2002), 41-45.

Azkarate, A. y Sánchez Zufiaurre, L. 2005: Aportaciones al conocimiento de las técnicas constructivas altomedievales en Álava, Guipúzcoa y Vizcaya, en "Aparejos constructivos medievales en el Mediterráneo Occidental. Estudio arqueológico de las técnicas constructivas», monográfico de Arqueología de la Arquitectura, 4, 193-213.

Azkarate, A. y Lasagabaster, J. I. 2006: La Arqueología y la recuperación de las «arquitecturas olvidadas». La catedral de Santa María y las primitivas murallas de Vitoria-Gasteiz, Congreso Internacional "Restaurar la Memoria». Arqueología, Arte y Restauración, AR\&PA (Valladolid 2004), Salamanca, 137-160.

Brogiolo, G. P. 1995: Arqueología estratigráfica y restauración, Informes de la Construcción, 435, 31-36.

Caballero Zoreda, L. 1997: En torno a algunas experiencias de lectura arqueológica de edificios, "El monument, document» (Barcelona 1996), Quaderns Científics i Tècnics, 9, 307-324.

Caballero Zoreda, L. 2002: Sobre historia y restauración del monumento (o de la diferencia entre San Juan de Baños y el Taj Mahal), «I Biennal de la Restauració Monumental» (L'Hospitalet de Llobregat 2000), Quaderns Científics de Restauració Monumental, 13, 41-51.

Caballero Zoreda, L. 2006a: Arqueología de la Arquitectura. Conocimiento y restauración, Congreso Internacional "Restaurar la Memoria». Arqueología, Arte y Restauración, AR\&PA (Valladolid 2004), Salamanca, 161-179.

Caballero Zoreda, L. 2006b: Arqueología de la Arquitectura. Conocimiento e intervención, «Património Arquitectónico. Registo, Interpretação e Criterios de Intervenção" (Lisboa 2005), Património estudos, 9, 33-43.

Doglioni, F. 1997: Stratigrafia e restauro. Tra conoscenza e conservazione dell'architettura, LINT, Trieste.

Doglioni, F. 2002: Ruolo e salvaguardia delle evidenze stratigrafiche nel progetto e nel cantiere di restauro, Arqueología de la Arquitectura, 1, 113-130. 
Doglioni, F. 2008: Nel restauro. Progetti per le architetture del passato, Marsilio editori, IUAV, Venezia.

Ferrando, I., Mannoni, R. y Pagella, R. 1989: Cronotipologia, Archeologia Medievale, 16, 647-661 (reeditado en Mannoni, R. 1994: 3. Caratteri Costruttivo dell'edilizia storica, escum, Genova, 77-91).

Francovich, R. 1985: Contributi per l'unità della disciplina. Archeologia e restauro: da continguità a unitarietà, Restauro \& Città, 1, fasc. 2, 11-20.

Francovich, R. 1988: Archeologia e restauro dei monumenti. Nota introdutiva, en Francovich y Parenti, Archeologia e restauro dei monumenti (Certosa di Pontignano 1987), Firenze, 13-27.

Gabrielli, F. 1996: La "cronotipología relativa» como metodo di analisi degli elevati: la facciata del Palazzo Pubblico di Diena, Archeologia dell'Architettura, $1,17-40$.

Harris, E. C. 2003: Estratigrafía de estructuras en pie, Gabinete de Arqueología, 3, 79-87; reeditado en el mismo año: The Stratigraphy of Standing Structures, Archeologia dell'Architettura, 8, 9-14.

Latorre, P. y Cámara, L. 2002: Los procesos de transformación de la arquitectura en el tiempo. Consecuencias teóricas y metodológicas en el proyecto y la obra de restauración, «I Biennal de la Restauració Monumental» (L'Hospitalet de Llobregat 2000), Quaderns Cientifics i Tècnics de Restauració Monumental, 13, 161-175.

Mileto, C. y Vegas, F. 2006: El edificio y su memoria. Conservación de las huellas del pasado, «Património Arquitectónico. Registo, Interpretação e Criterios de Intervenção" (Lisboa 2005), Património estudos, 9, 72-89.

Parenti, R. 1985: La lettura stratigrafia delle murature in contesti archeologici e di restauro architettonico, Restauro \& Città 2, 55-68.

Quirós Castillo, J. A. 1996: Indicadores cronológicos de ámbito local: cronotipología y mensiocronología, en Caballero, L. y Escribano, C. (eds.): Arqueología de la Arquitectura. El método arqueológico aplicado al proceso de estudio y de intervención en edificios históricos (Burgos), "Actas», Salamanca, 179-187.

Sánchez Zufiaurre, L. 2007: Técnicas constructivas medievales. Nuevos documentos arqueológicos para el estudio de la alta Edad Media en Álava, Vitoria-Gasteiz.

Recibido: 24 de junio de 2009

Aceptado: 21 de septiembre de 2009 